\title{
PARACETAMOL INDUCED ANGIOEDEMA
}

Sir,

This communication describes a 4-year-old boy with a presumed viral infection who developed allergic rash and angioedema probably related to paracetamol exposure. The child presented with history of fever and minute maculopapular rash, which began on the buttocks and spread to involve the entire body (day 1 ). On day 3 , he received 2 doses of syrup paracetamol (acetaminophen, $15 \mathrm{mg} / \mathrm{kg} /$ dose) from his general practitioner. Within an hour of receiving the dose, the child developed edema of the lips, along with massive dermal edema which initially involved the periorbital region and the face and later spread to involve the trunk and the limbs. The edema was accompanied by rash in the form of discolored patches, which was morphologically distinct from the maculopapular rash which the child had developed on day 1. Unaware of the association between rash and the paracetamol, the patient continued to receive the drug for high fever (20 $\mathrm{mg} / \mathrm{kg} / \mathrm{dose}$, twice daily - day 4) on the advice of the practitioner. No other medication was given. On the following day (day 5), he was hospitalized under our care due to abdominal pain, vomiting, and discolored patches (rash) on the face, hands, and feet. On examination, the child's vital parameters were stable. Edema and the rash involved the entire body, including the upper lip and scrotum. The throat and conjunctivae were congested. The systemic examination did not reveal any abnormal finding. The child's hematological and biochemical parameters were within normal limits. Chest radiograph revealed prominence of broncho-vascular markings, and ultrasound of the abdomen did not reveal any abnormality. Tests for hepatitis B, leptospirosis, and dengue infections were nonreactive.

Suspecting an adverse event, the administration of paracetamol was stopped. The child received injection hydrocortisone $(15 \mathrm{mg} / \mathrm{kg} / \mathrm{d}$, once daily for 2 days), along with a single dose of $1 \mathrm{cc}$ chlorpheniramine maleate. The edema subsided within 4 to 5 hours after the child received hydrocortisone. He was treated with syrup 
hydroxyzine $(1 \mathrm{mg} / \mathrm{kg} / \mathrm{d})$, syrup erythromycin (30 mg/kg/d in 3 divided doses), application of calamine lotion and tepid sponging for 3 days. The fever and rash subsided over the next 4 days, and the child was discharged on day 9 . Causality analysis (Naranjo's algorithm) ${ }^{[1]}$ gave a score of 6 (probable reaction).

Paracetamol is a widely used antipyretic agent with an excellent safety record. However, in a few patients, skin and respiratory symptoms, immediate urticaria, angioedema, ${ }^{[2]}$ fixed drug reactions, ${ }^{[3]}$ and anaphylaxis ${ }^{[4]}$ have been reported to be associated with exposure to the drug. The worsening of manifestations on continued exposure and amelioration of manifestations following drug withdrawal in this case point towards a probable causal role of paracetamol. Since the character of the rash on exposure to paracetamol (urticaria/angioedema) was quite different from the initial rash (maculopapular), the former is unlikely to represent accentuation of the rash associated with presumed viral infection.

In susceptible patients, angioedema has an abrupt onset and commonly involves the eyes, lips, hands, and the feet. The edema may also involve the throat (leading to hoarseness and dyspnea) and the Gl tract (leading to vomiting, diarrhea followed by abdominal pain and anorexia). ${ }^{[5]}$ Nonsteroidal anti-inflammatory drug (NSAID including aspirin) use has a higher propensity to be associated with urticaria, angioedema, and pruritus caused by non-allergic reactions due to inhibition of isoform 1 of cyclooxygenase (COX 1). Although the exact mechanism for occurrence of angioedema is yet to be fully elucidated, it is presumed to be a hypersensitivity reaction (allergic or non-allergic) to a toxic metabolite of paracetamol. Despite paracetamol being metabolized to highly reactive metabolites, these reactions are only infrequently reported because it is only a weak inhibitor of prostaglandin synthesis. Most patients (though not all) with hypersensitivity to paracetamol also have hypersensitivity to NSAIDs. ${ }^{[2]}$ But paracetamol is associated with hypersensitivity reactions in less than $5 \%$ of those who are known to be sensitive to NSAIDs. [6] This limits the choice of antipyretic agents that can be administered to patients with paracetamol hypersensitivity. Given the cross-reactivity with NSAIDs, they should be used with caution in these subjects, and parents may have to rely more on physical measures (like tepid sponging) for controlling fever in such children.

TANMAY S. PANCHABHAI, NITHYA J. GOGTAY, SANDEEP B. BAVDEKAR ${ }^{1}$ Departments of Clinical Pharmacology and ${ }^{1}$ Pediatrics, Seth GS Medical College and KEM Hospital, Mumbai, India

Correspondence: Dr. Tanmay S. Panchabhai, Department of Clinical Pharmacology, New MS Building, 1st Floor, Seth GS Medical College and KEM Hospital, Parel, Mumbai - 400 012, India E-mail: tspanchabhai@ hotmail.com

\section{REFERENCES}

1. Naranjo CA, Busto $U$, Sellers EM, Sandor $P$, Ruiz I, Roberts EA, et al. A method for estimating the probability of adverse drug reactions. Clin Pharmacol Ther 1981;30:239-45.

2. Boussetta K, Ponvert C, Karila C, Bourgeois ML, Blic J, Scheinmann P. Hypersensitivity reactions to paracetamol in children: A study of 25 cases. Allergy 2005;60:1174-7.

3. Prabhu MM, Prabhu S, Mishra P, Palaian S. Cellulitis-like fixed drug eruption attributed to paracetamol (acetaminophen). Dermatol Online J 2005;11:24.

4. Gowrinath K, Balachandran C. Anaphylactic reaction due to paracetamol. J Indian Med Assoc 
2004;102:223-6.

5. Austen KF. Allergies, anaphylaxis and systemic mastocytosis. In: Kasper DL, Braunwald E, Fauci AS, Hauser SL, Longo DL, Jameson JL, editors. Harrison's Principles of Internal Medicine. 16th ed. New York, USA: McGraw Hill; 2005. p. 1947-56.

6. Szczeklik A. Analgesics, allergy and asthma. Drugs 1986;32:148-63. 